\title{
As percepções dos farmacêuticos sobre seu trabalho nas farmácias comunitárias em uma região do estado do Rio de Janeiro
}

\author{
The pharmacist's perceptions about their job \\ at communitarian pharmacies of the state of Rio de Janeiro
}

Cláudia Regina Garcia Bastos ${ }^{1}$

Rosângela Caetano ${ }^{2}$

${ }^{1}$ Conselho Regional de Farmácia do Estado do Rio deJaneiro. RuaAfonso Pena 115, Tijuca. 20270- 971 Rio deJaneiro RJ. crgbastos@uol.com.br

${ }^{2}$ Instituto de M edicina

Social, U niversidade do

Estado do Rio deJaneiro.
Abstract Theaim of thisstudy was to understand the pharmacist's perceptions that work at communitarian pharmacies from Rio de Janeiro about their professional practices and how this vision can be related to the practice implementation of Pharmaceutical Attention. A qualitative research was developed with the execution of semi-structured interviews; subsequently discourse was submitted to content analysis, through the thematic analysis. This research have been made with 15 pharmaceuticals of Rio de Janeiro state pharmacies with proportional distribution corresponding to the following typology: state pharmacy network; local network; and familiar, without branches. The speech classification which was made here has shown at least three convergences: the continue difficulties of the population about the use of medicines, certain migration of the pharmaceutical practice, in the meaning of (re) valuing the patient and the superficial knowledge about the Attention Pharmaceutical conception. It is necessary to intensify a reflection on this issue to lead us to identify elements that can guarantee that this pharmaceutical practice can be implemented as a complementary health service.

Key words Pharmaceutical profession, Profession practice, Attention Pharmaceutical, Community pharmacy
Resumo Estetrabalho tevepor objetivo compreender as percepções de farmacêuticos de farmácias comunitárias do estado do Rio de Janeiro sobre suas práticas profissionais e como estas poderiam estar relacionadas com a implantação da Atenção Farmacêutica. Foi desenvolvido um estudo qualitativo, com a realização de entrevistas semiestruturadas, posteriormente submetidas à análise de conteúdo baseada na análise temática das falas. A população de estudo foi composta por quinze farmacêuticos responsáveis técnicos de farmácias comunitárias do estado, com distribuição equânime segundo a seguinte tipologia: farmácias deredeestadual, de rede local e farmácias consideradas familiares, sem filiais. A categorização do discurso dos farmacêuticos mostrou, pelo menos, três convergências: as contínuas dificuldades da população quanto ao uso de medicamentos, certo deslocamento da prática, no sentido de (re) valorizar o paciente, e um conhecimento bastante superficial do conceito de Atenção Farmacêutica. Faz-se necessário ampliar as reflexões sobre esse tema, de modo a identificar elementos que possam vir a garantir que a práxis farmacêutica se insira com complementaridade nos serviços de saúde. Palavras-chave Profissão farmacêutica, Prática profissional, Atenção Farmacêutica, Farmácia comunitária 
Introdução

A farmácia tem fundamental importância como porta de acesso da população em relação ao consumo de medicamentos e devia ser entendida como um posto avançado de atenção primária de saúde. Segundo dados do M inistério da Fazenda ${ }^{1}$, as farmácias e drogarias seriam responsáveis por $76 \%$ do fornecimento direto de medicamentos à população.

Farmácias comunitárias referem-se aos estabelecimentos do comércio varejista privado tendo o farmacêutico como responsável técnico, atendendo às exigências da Lei n 5.991/73 do M inistério da Saúde². É necessário destacar que, neste trabalho, o termo farmácia comunitária exclui as farmácias de manipulação e as farmácias públicas, referindo-se tão somente às farmácias ditas comerciais e drogarias. N estas, 0 atendimento ao paciente acontece no nível de atenção primária à saúde, com a responsabilidade técnica, legal e privativa de farmacêutico.

Sendo assim, a farmácia comunitária ocupa um importante espaço no cenário da saúde pública brasileira, como local de dispensação de medicamentos edecontínua promoção do consumo de medicamentos para a população. N elas, o usuário busca, através do consumo de produtos, prescritos ou não, o restabelecimento da sua saúde.

Entretanto, ainda que o medicamento seja de fundamental importância para o paciente, tornando-se um componente estratégico na terapêutica ena manutenção de melhores condições de vida do indivíduo, éfundamental quenão nos esqueçamos da necessidade de fornecer à sociedade informações seguras que minimizem o risco à saúde, que pode ser causado se o medicamento não for utilizado de modo adequado, efe tivo e seguro. E a farmácia comunitária, pelo espaço que ocupa no processo de aquisição e dispensação desses produtos, pode ser um lócus importante para a realização de práticas que fomentem seu uso mais seguro e racional. A pre sença ea ação do farmacêutico nesses estabelecimentos se fundamentam no fato de que 0 uso racional do medicamento requer a aplicação de um conhecimento técnico-científico aprofundado sobre as suas características intrínsecas, pelas reações e interações adversas que podem desencadear, e sobre as doenças para as quais são úteis.

Os modelos tradicionais de prática farmacêutica têm sua preocupação principal voltada para os cuidados com o medicamento. N essesentido, o foco de trabalho do farmacêutico se dire ciona para planejamento, síntese, produção, abastecimento, distribuição e controle de qualidade dos medicamentos. Em decorrência desse foco, sua prática mostra-se pouco efetiva sobrea morbimortalidade relacionada a medicamentos ${ }^{3}, 0$ quetem levado ao surgimento de al gumas novas propostas de prática profissional na profissão farmacêutica. Dentre esses novos caminhos, há a Atenção Farmacêutica, que se apresenta como uma alternativa - implementada ou em implementação em diversos países ${ }^{4}$ - que visa redirecionar o objetivo do trabalho do farmacêutico para o indivíduo que necessita e usa os medicamentos, no sentido de melhorar a qualidade do processo de utilização de medicamentos pela população. $\mathrm{Na}$ A tenção Farmacêutica, a perspectiva profissional do farmacêutico seria a de assumir a responsabilidade de identificar e resolver as necessidades do paciente em relação aos medicamentos, e responder por esse compromisso ${ }^{5}$. Conforme alerta Cipolle 6 , essa reorientação da atenção profissional parte do conceito de que não são os fármacos que têm doses, mas são as pessoas que recebem as doses, e que essas doses demedicamentos (eesses medicamentos) devem ser adequadas às suas necessidades individuais.

Acompanhando os avanços na discussão da promoção do uso racional de medicamentos, foi elaborada no país, em 2002, uma proposta de Consenso Nacional de Atenção Farmacêutica ${ }^{7}$, que define essa Atenção como parte integrante da Assistência Farmacêutica, na perspectiva da integralidade das ações de saúde. A concepção subjacente seria de que a Atenção Farmacêutica se referiria às ações de cuidado do farmacêutico com o indivíduo no sentido de promover o uso racional dos medicamentos e a melhoria da qualidade de vida. Já a Assistência Farmacêutica seria um conjunto mais amplo de atividades relacionadas com o medicamento, envolvendo o farmacêutico e outros profissionais de saúde, destinadas a apoiar as ações de saúde relacionadas com o medicamento, definidas pela Política $\mathrm{Na}$ cional de M edicamentos ${ }^{8}$.

Esse modelo de atenção também indica o caminho que o farmacêutico devetrilhar no sentido de recuperar o compromisso na prevenção de doenças, promoção e recuperação da saúde, de forma integrada à equipe de saúde. Esse novo modo de exercer a prática profissional muda o objeto central da atuação do profissional farmacêutico, que deixa de ser o medicamento, em si mesmo, voltando a ser o usuário ea comunidade como um todo.

A despeito desses movimentos, observa-sena literatura uma escassez de trabalhos referentes à percepção do farmacêutico quanto a sua prática profissional, seja em farmácias públicas ${ }^{9}$, seja em 
farmácias comunitárias privadas. Estefan ${ }^{10}$ járessaltava a necessidade urgente de se compreender e assimilar a essência da identidade da profissão farmacêutica, bem como do contexto em que ela se insere, como mecanismo que propicie conhe cer a realidade e planejar o futuro da profissão.

D esse modo, compreender as percepções que esses profissionais têm de sua práxis e dos processos de trabalho presentes nas farmácias comunitárias podeajudar a identificar o modusope randi dessa prática e onde há estrangulamento de interesses que desfocam o objetivo das farmácias como estabelecimentos produtores de saúde para estabelecimentos estritamente comerciais. Essa identificação, portanto, pode ser de auxílio na elaboração de caminhos e estratégias queavancem na efetiva implementação da Atenção Farmacêutica e de outras práticas assistenciais em nosso meio, melhorando a segurança, a eficácia e o uso racional dos medicamentos.

Este artigo é um recorte da dissertação de mestrado de uma das autoras ${ }^{11}$ e teve como objetivo identificar a concepção que os farmacêuticos responsáveis técnicos, atuantes em farmácias comunitárias do estado do Rio de Janeiro, têm sobre a sua prática profissional e como essa visão pode estar relacionada à/e facilitar a implementação de práticas focadas no paciente, tais como a Atenção Farmacêutica.

\section{Metodologia}

Trata-se de um estudo qualitativo, de estratégia metodológica descritiva e analítica. Foram realizadas entrevistas semiestruturadas com farmacêuticos responsáveis técnicos de farmácias do estado do Rio de Janeiro que atuavam em três tipos defarmácias comunitárias, de modo a contemplar farmácias de rede estadual, farmácias de rede local e farmácias familiares.

0 critério de seleção dos entrevistados foi 0 de escolha dos farmacêuticos responsáveis técnicos entre os que trabalhassem em um desses três tipos de farmácias comunitárias por no mínimo vinte horas semanais.

A abordagem utilizada nas entrevistas fez com que os entrevistados rememorassem suas traje tórias profissionais desde o primeiro emprego como farmacêutico, bem como descrevessem suas atividades em um dia típico na farmácia comunitária e enumerassem aquelas atividades consideradas como mais importantes e/ ou mais difíceis de serem realizadas. Foram ainda exploradas suas vivências no balcão da farmácia, as descrições das tarefas de dispensação de medicamen- tos e seus desdobramentos, com ênfase na questão do medicamento genérico e nas dificuldades da população no uso de medicamentos.

$\mathrm{N}$ a seleção dos informantes para as entrevistas, houve a preocupação e o cuidado em evitar a possibilidade de introdução de vieses decorrentes do fato de a pesquisadora que conduziu as entrevistas ser farmacêutica fiscal do Conselho Regional de Farmácia do Estado do Rio de aneiro (CRF-RJ). Logo, as entrevistas foram realizadas apenas em farmácias de áreas cuja fiscalização não fosse ou já tivesse sido de sua responsabilidade. Buscou-se com isso que a adesão ao estudo e as respostas tivessem motivação espontânea dos farmacêuticos e não decorressem da identificação do pesquisador com a figura de um agente que estaria ali para fiscalizar seus atos.

Os farmacêuticos responsáveis técnicos selecionados trabal havam em estabelecimentos dos municípios de São Gonçalo, Tanguá, Rio Bonito e I taboraí. São Gonçalo está inserido na chamada Região M etropolitana do Rio de Janeiro eé o segundo município em densidade demográfica do estado do Rio, tendo passado por um processo de desindustrialização nasúltimas décadas. Os demais municípios fazem parte do eixo do Leste Fluminense, com economia predominantemente rural e estão, em média, cinquenta quilômetros distantes da capital.

O trabal ho decampo se desenvolveu em 2006, ao longo de um mês, iniciando-se pelas farmácias da periferia do município de São Gonçalo. Todos foram individualmente esclarecidos sobre os objetivos da pesquisa e se posicionaram sobre sua participação através de um termo de consentimento livreeesclarecido, obedecendo às normas estabelecidas pela Comissão $\mathrm{N}$ acional de Ética em Pesquisa (Conep) ${ }^{12}$.

$\mathrm{Na}$ etapa de coleta de dados, a definição de fechamento amostral aconteceu à medida que, na avaliação da pesquisadora, as informações fornecidas pelos novos participantes da pesquisa pouco acrescentavam ao material já obtido, não mais contribuindo de modo significativo para o desenvolvimento da reflexão teórica das percepções sobre as práticas profissionais realizadas no universo estudado na pesquisa, como ressaltado por Fontanella et al. ${ }^{13}$.

A análise dos dados privilegiou a compreensão e a interpretação das percepções a partir dos discursos dos entrevistados. 0 exame do material obtido nas entrevistas seguiu a análise de conteúdo proposta por Bardin ${ }^{14}$, segundo a qual os dados das entrevistas foram codificados segundo as seguintes categorias analíticas: (1) prática profissional; (2) dificuldades da população no 
uso de medicamentos; ( 3 ) satisfação dos farmacêuticos na farmácia; e (4) significados atribuídos ao termo Atenção Farmacêutica. Além disso, procedeu-se ao desenho de um breve perfil dos entrevistados, buscando poder contextualizar eexplorar eventuais percepções esentidos que pudessem estar relacionados ao local de atuação profissional, tempo de formado e de atuação na profissão e em farmácias comunitárias, tempo deexercício naqueleestabelecimento em questão e habilitações adicionais.

A identificação das concepções buscou compreender o significado desse trabalho para os profissionais e o modo como ele era efetivamenteexecutado no dia a dia. Entendemos quea forma como se organiza o trabalho cotidiano guarda, em última instância, uma profunda relação com as concepções acerca da prática, conduzindo ao modelo concretamente operado de prática profissional farmacêutica vigente.

\section{Resultados ediscussão}

Perfil dos entrevistados

Foram realizadas 15 entrevistas, com distribuição equânime do número de entrevistados pel os três tipos deestabel ecimentos examinados: farmácias familiares, farmácias de redes locais e de redes estaduais.

Sete dos entrevistados eram homens. N as farmácias familiares, todos os entrevistados eram do sexo masculino, situação inversa da observada naquelas de rede local. A pesar de a idade variar entre 22 e 76 anos, e o tempo de formado variar entre 2 e 56 anos, a maioria erajovem e tinha pouco tempo deformado. Em decorrência, a experiência profissional da maioria deles era bem recente, com três anos ou menos de atuação como farmacêuticos. Todos os entrevistados atuavam profissionalmente como farmacêuticos desde a saída da faculdade, não se observando qualquer padrão específico segundo o tipo de estabel ecimento.

0 grau de qualificação encontrado em todas as tipologias de estabelecimento estudadas indicou a presença do empenho pessoal e intelectual dos farmacêuticos em obter conhecimentos técnicos que proporcionassem condições de estarem inseridos com diferencial no mercado detrabalho. Contudo, o maior percentual de farmacêuticos com habilitações (principalmente em bioquímica), especializações e pós-graduação estava presente nos segmentos de farmácias de rede local e estadual, talvez como uma exigência demercado. Sobresuas atividades pregressas, que podia Ihes conferir um grau de experiência profissional acumulada que facilitasse suas atividades cotidianas, observou-se que $80 \%$ dos entrevistados trabalharam em outros locais, como farmacêuticos, antes de estarem no exercício da responsabilidade técnica atual. Do total deentrevistados, a maioria relatou não trabalhar, no momento da entrevista, em outro local, sendo uma constante a observação de dedicação exclusiva no grupo de farmacêuticos proprietários, independentemente da tipologia de farmácias.

\section{A prática profissional \\ nas farmácias comunitárias}

$N$ aves et al. ${ }^{15}$ assinalam que, no Brasil, há uma série de peculiaridades em relação ao comércio varejista de medicamentos. Uma delas refere-se ao fato de a maior parte deste segmento ser composta de proprietários leigos, não havendo mecanismos para impedir a abertura de novas farmácias por eles. Nessecontexto, basta queafarmácia atenda às exigências sanitárias locais efederais, quanto à estrutura física e aos requisitos legais, eque contrate um farmacêutico responsável técnico, para poder abrir e funcionar. Os demais funcionários desses estabelecimentos têm, via de regra, baixa escolaridade $^{16}$, não havendo, na maioria dos casos, exigências de qualificação prévia para fazer parte do quadro de funcionários de uma farmácia. Como decorrência, não é incomum que profissionais leigos sem qual quer formação ou qualificação específica na área da saúde estejam, nesses estabelecimentos, em contato direto com o público e com o processo de atendimento de suas necessidades, em termos de aquisição e orientação no consumo e uso dos medicamentos.

Tivemos o momento de pegarem o segurança e colocarem no bal cão, sem noção de nada, para atender os clientes. Não éfácil. Por enquanto, acontece uma coisa peculiar: o nosso gerente é o gerente dos laticínios... 0 chefe dos laticínios é o chefe da drogaria. Elenão entendenada da drogaria, tanto que ele nem vem aqui (farmacêutico de farmácia de rede estadual).

Outro elemento destacado pelos entrevistados dizia respeito ao contexto de incremento de vendas pela indústria farmacêutica, que chega a atingir os medicamentos genéricos, expressando também uma mudança nas estratégias de competição do segmento industrial a partir do final dos anos 90, quando é regulamentada a Lei dos Genéricos ${ }^{17}$. As empresas produtoras - não apenas de similares, mas também de medicamentos genéricos e de referência - concorrem entre si, fornecendo bônus, comissões e outras vantagens 
comerciais sobre venda de determinados medicamentos, e fazendo da propaganda, nos meios de comunicação, um instrumento de sedução ao uso de medicamentos por conta própria.

Todas as indústrias, atualmente, dão comissão para as farmácias, mas depende muito do laboratório. Genérico e "éticos" estão dando comissão também. D ependendo do produto, chega atéa $40 \%$, $45 \%$ e, também, dependendo da quantidade. M esmo assim, quando você compra, eles dão no máximo $35 \%$, mas se for comprar para três ou quatro Iojas, tipo essas redes que existem, o desconto é maior. [Laboratório de] referência dá bonificação. Antes do genérico, não dava, mas hoje dá ( farmacêutico de farmácia familiar).

Arguídos sobre as atividades que consideravam mais importantes no seu dia a dia nas farmácias, as opiniões dos farmacêuticos muitas vezes migraram para o trabalho de cuidado ao paciente, sendo demonstrada sua preocupação quanto ao uso adequado de medicamentos, às interações medicamentosas potenciais e à dificuldade de entendimento do que estava prescrito no receituário por parte do usuário. Além disso, sobrea prática profissional dos entrevistados nas três tipologias analisadas, observou-se uma prioridade de ações no sentido do controle efetivo dos medicamentos vendidos com retenção de receita, conforme a Portaria n ${ }^{\circ} 344 / 98$ SV S/M S ${ }^{18}$.

A cultura do controledemedicamentosespecíficos, como é o caso dos entorpecentes e psicotrópicos, ainda marca a práxis desses farmacêuticos. Isso contribui para a existência de tensões no ambiente de trabalho nas farmácias comunitárias, principalmente no que se refere a práticas relacionadas com a Atenção Farmacêutica. Como exemplo, relata-se desde a pouca autonomia para atuarem no cuidado direto ao paciente, como a imposição de muitas farmácias para que o farmacêutico se desl oque para atividades administrativas, como o lançamento de notas fiscais de todos os medicamentos comercializados ea atividade de gerência. Ficou patente também, em al guns discursos, a resistência dos balconistas a acatarem orientações dosfarmacêuticos, ficando claras as limitações existentes para o melhor desempenho profissional, em especial no que se refere às atividades de dispensação e orientação aos pacientes. Essas atividades, muitas vezes, são realizadas por profissionais de venda, com formação inadequada a essas ações e, em alguns casos, com motivações para ganhos adicionais vinculados às estratégias de competição das firmas produtoras dos medicamentos.

A dispensação de medicamentos é com os balconistas, os [medicamentos] controlados, sou eu. É assim: chega a receita, tem 0 genérico e o similar que é mais barato. Geralmente, o diente leva 0 mais barato. Eles entregam o medicamento. $\mathrm{Na}$ maioria das vezes, eu faço serviço burocrático, lançando nota fiscal. É raro eu participar da dispensação. Só quando écontrolado mesmo. Antigamente, era a subgerente que lançava as notas fi scais da Ioja; depois que ela saiu, eu fiquei lançando. Se eu não tiro dúvidas, o balconista tira. No início, quando eu via erros (dos balconistas), eu falava muito, depois eu fui parando. Eu estou em farmácia só há dois anos, já os balconistas tem mais tempo (farmacêutico de farmácia de rede local).

Eu assumi a farmácia. Deixei de ser farmacêutica e me tornei administradora (farmacêutica de farmácia de rede local).

Zubioli ${ }^{19}$ já apresentava o panorama de ambiguidadee conflito com que o farmacêutico viria a conviver na farmácia comunitária, devido ao aspecto comercial nesse ambiente, eo contraponto das atividades real izadas pelo farmacêutico em prol da saúde dos consumidores. Esse panorama complexo fica também bastante evidentequando os farmacêuticos entrevistados elencam o conjunto amplo deatividades executadas como parte deseu exercício profissional nas farmácias comunitárias: dispensação de medicamentos aos usuários; intercambialidade demedicamentos prevista pela legislação, confirmação junto ao prescritor de dúvidas no receituário; uso de bibliografia farmacêutica para consulta; controle da validade do estoque de medicamentos; controle de estoque dos medicamentos constantes na Portaria ${ }^{\circ}$ 344/98 SV S/M S; manutenção da documentação do estabelecimento devidamenteorganizada bem como dos padrões de higiene, de acordo com as normas sanitárias; treinamento de funcionários; e gerenciamento da farmácia. A despeito desse espectro amplo de atribuições eatividades, o diálogo estabelecido com os profissionais indicou, em recorrentes falas, seu interesse e a preocupação com a fragilidade dos pacientes no seu contato com o medicamento. Também de forma uníssona, ecoou nos discursos dos farmacêuticos a demonstração desolidariedadeparacom eles, ainda que esta nem sempre se expresse em uma atitude concreta no cotidiano do trabalho.

Foram citadas, também, as dificuldades com a legibilidade das prescrições, oriundas em particular da letra do profissional médico, como um fator limitante para a efetiva e segura dispensação de medicamentos; e a legislação que, segundo os farmacêuticos, se modifica rápida e constantemente. Entender as normas sobre a dispensação de medicamentos controlados também foi mencionado como um fator de dificuldade, percebido principalmenteno início da carreira farmacêutica. 
Quando perguntados sobre que atividade consideravam como sendo de mais fácil execução no dia a dia profissional, grande parcela dos farmacêuticos - das três tipologias de farmácia apontou o lançamento de medicamentos controlados no livro de registro aberto especificamente para esse fim. Na verdade, esse monitoramento se resume, via de regra, em uma operação aritmética básica de controle de estoque de medicamentos, em que são indicadas a entrada e a saída dos medicamentos em um livro específico, através dos seus respectivos documentos (nota fiscal de compra do medicamento e registro da receita, conforme preconiza a legislação). Embora não encerre em si grandes dificuldades, essa atividade consomesignificativo tempo de execução, cuja ordem de grandeza é diretamente proporcional ao volume de vendas desse tipo de medicamentos pelo estabelecimento, e é objeto de fiscalização rigorosa e sistemática pelos diversos órgãos responsáveis, tais como a Vigilância Sanitária M unicipal, o Conselho Regional deFarmácia e a Delegacia de Crimes contra a Saúde Pública. Esse atendimento às exigências legais contribui para/e termina por afastar o profissional do atendimento e cuidado direto aos usuários, dificultando as ações mais voltadas para a Atenção Farmacêutica.

Dificuldades da população

no uso dos medicamentos

0 paciente deve ser visto não apenas como um corpo, com seu funcionamento biológico, mediado por uma gama de processos físicos e químicos, mas também como a amálgama de processos sociais, políticos e culturais historicamente construídos que incidem sobre ele ao longo de sua vida ${ }^{20}$. O conjunto de costumes, valores, crenças, saberes e experiências que el e possui sobre o medicamento e o resultado que dele se quer obter é somado às incertezas e aos medos vivenciados por cada indivíduo, na busca do restabelecimento do seu equilíbrio orgânico. Vê-se, então, que as formas de pensar e agir ante 0 uso de medicamentos se constroi individualmente, sendo seu uso modulado, também, pela forte mídia da indústria farmacêutica e pela facilidade com que, de modo geral, se podem adquirir quaisquer tipo de medicamentos nas farmácias comunitárias. Esse somatório tende a organizar o comportamento que a maioria das pessoas tem ante o uso de medicamentos, levando-se em conta ainda que a população tem ao seu dispor, além dos medicamentos como fonte de terapia médica científica, a terapia popular, pelo uso recorrente de chás e emplastos; a terapia natural, pelo consumo de plantas e fitoterápicos, sem prescrição médica; e a terapia religiosa, como as rezas e benzeduras, fruto da compreensão de que o processo de cura envolve, além do corpo, o espírito ${ }^{21}$.

Para a maioria dos informantes, as dificuldades da população quanto ao uso dos medicamentos podem ser sumarizadas em um tripé: a ilegibilidade da letra do prescritor, a não compreensão sobre o uso dos medicamentos por parte dos consumidores e o custo dos medicamentos.

Este último elemento é de grande relevância para o consumidor no momento da compra do medicamento. Segundo Luiza e Bermudez ${ }^{22}$, a questão do poder de compra do usuário é um dos fatores decisivos para 0 acesso aos medicamentos, devendo existir a compatibilidade entre o preço do medicamento e a capacidade aquisitiva dos usuários para que se realize esse acesso.

No decorrer das entrevistas, vários farmacêuticos relataram que o cliente quer entender/conhecer, no corpo da receita, qual produto éo "mais importante" para sua recuperação, para poder eleger a compra deste, desprezando a aquisição dos demais medicamentos prescritos, em face da falta de condições econômicas para comprá-los.

Eles questionam muito a medicação prescrita. $M$ uitos deles cortam pela metade a receita, inclusive perguntam: "Q ual que é para dor? M e vê o da dor. Esse médico está achando o quê? Q ue eu sou milionário?" (farmacêutico de farmácia de rede estadual).

Satisfação dos farmacêuticos

com o trabalho na farmácia

No tocante à satisfação dos farmacêuticos no ambiente da farmácia, foram feitos quatro blocos de perguntas: sobre a satisfação intrínseca ao trabalho, em relação às condições de trabalho, à sua organização e sobre os vínculos sociais do trabalho.

Os farmacêuticos deram depoimentos contraditórios quanto à satisfação de estar trabaIhando na farmácia comunitária. Uma gama de pressões é sentida pelos farmacêuticos; entre as mais citadas, estão a questão da desvalorização salarial; o não reconhecimento pela equipe, epela população em geral, do papel do farmacêutico; a sensação de abandono pelos órgãos profissionais, sindicatos e governo; a impossibilidade de continuar os estudos, que lhe garantiria maior qualidade do trabalho realizado; o número insuficiente de funcionários na farmácia; e o conflito entre as autoridades administrativa e profissional. 
Em oposição a esse contexto, foram também fornecidos depoimentos em que aparecem, de forma significativa, a percepção de vitória, de conquista, de sensação de dever cumprido, espeIhadas principalmente pel os farmacêuticos mais experientes de rede estadual e farmacêuticos de farmácias familiares, de modo geral.

Destaca-se que a autonomia para a construção do seu dia a dia é percebida, com mais frequência, nesses dois últimos grupos de farmacêuticos citados. Em contrapartida, os mais jovens e com menor bagagem profissional trazem uma carga de sofrimento com o desenrolar de seu cotidiano, com sentimentos de desvalorização e desesperança ante as expectativas profissionais.

Éboli ${ }^{23} \mathrm{lembra}$ que, para que a satisfação profissional seja completa, ela deveser dialética; nesse sentido, ressalta a importância da satisfação do farmacêutico no seu trabalho diário como fundamental para o bom desenvolvimento técnico e profissional.

Vale pontuar que os depoimentos indicaram o inconformismo ante a ausência de espaços mínimos para o desenvolvimento das suas atividades e quanto à organização do estabelecimento direcionado unicamente para o foco comercial e administrativo enão técnico e de cuidado. Como exemplo, houverelatos de ausência atédemobiliário - cadeira e mesa - que permitisse ao farmacêutico poder se sentar no decorrer do seu expediente, inclusive no momento de escriturar as re ceitas de medicamentos ditos controlados. Muitos reclamaram denão possuírem um microcomputador, de modo a operacionalizarem os lançamentos dos dados dos medicamentos controlados, pelo menos na elaboração dos balanços trimestrais eanuais exigidos pela Portaria ${ }^{\circ} 344 / 98$, além de consultaram material específico que ajudasse a dirimir dúvidas próprias e dos pacientes. As condições de trabal ho são citadas como particularmenteinsatisfatórias, não apenas dificultando ações mais orientadas para a Atenção Farmacêutica, mas, sobretudo, permitindo ver que esta ainda está longe de ser considerada como uma atividade importante ou prioritária pelos donos dos estabelecimentos comerciais.

Eu acho que tinha que ter um espaço para o farmacêutico, para poder estar chamando e atendendo o paciente. M asum espaço mesmo, queninguém pudesse te interromper e o paciente pudesse contar realmente o que está se passando. Porque, num cantinho do balcão que a gente possa usar para falar com o cliente, às vezes el ese sente envergonhado de contar, às vezes éum homem querendo falar de um problema de disfunção erétil ou alguma coisa parecida. M esmo aqui dentro... É a mi- nha sala com o armário de controlados, não posso trazer para cá. As redes, a meu ver, teriam que investir mais no farmacêutico, nas suas condições de trabalho. Tinha que ter um sistema de computador para agilizar a confecção do balanço trimestral. la ser rapidinho, ao invés de ficar escrevendo (farmacêutico de farmácia de rede estadual).

Quanto à organização do trabalho, percebemos que, na maioria dos casos, os farmacêuticos concordavam com o modo como a farmácia se organizava estruturalmente. Muitos se sentiam identificados com a existência de regras, condutas e procedimentos internos, creditando a esses elementos uma certa segurança no trabaIho ali desenvolvido, apesar de muitas das vezes não concordarem com as regras ora impostas.

Quando indagados sobre a relação com os outros profissionais, surge como pano de fundo a disputa pelo espaço de poder e autonomia dentro da farmácia. Viu-se que os gerentes, e mesmo alguns balconistas, se opõem às orientações e determinações dadas pelos entrevistados. Suas falas mostram angústia einconformidade com a estrutura hierárquica sentida dentro desses estabelecimentos, que muitas vezes não considera os campos de atuação e os conhecimentos específicos de cada um dos grupos profissionais envolvidos no processo de atendimento e cuidado ao usuário.

Os farmacêuticos das redes, em particular, apontaram o estabelecimento das relações sociais no interior das farmácias como uma das mai ores dificuldades na sua atuação. Essas relações sociais assumem diversas interfaces, entre quais foram destacadas: 0 trabalho de convencer a equipe de bal conistas egerentes a colaborar, de modo a haver uma prática mais ética e menos comercial na farmácia; a resistência de alguns balconistas no sentido de implementar procedimentos orientados pelo farmacêutico; o fato de os clientes das farmácias confundirem sistematicamente o farmacêutico com o balconista; e o próprio exercício de estar em contato com o público, no esclarecimento de dúvidas, visto a falta ou precariedade de treinamento específico nas faculdades de farmácia, bem como a ausência, em boa partedos estabelecimentos, de condições de infraestrutura mínimas para que tal se realize com a privacidade, o sigilo e a ética necessários.

Já o desapontamento com a profissão foi constatado predominantementeno grupo defarmacêuticos mais jovens, independentemente da tipologia de farmácias em que trabalham, pois eles seviam inseridos em atividades que consideram marginais à sua profissão no seu cotidiano, tais como o trabal ho administrativo e a gerência das farmácias, em que não são considerados 
importantes os seus conhecimentos cognitivos referentes ao medicamento. Em contrapartida, à medida queo farmacêutico tinha experiência com a atenção ao paciente e atuava orientando-o sobre os cuidados com o uso dos medicamentos, era percebido um sentimento de satisfação com a profissão, ainda que os locais de trabalho fossem considerados inadequados.

Significado atribuído ao termo Atenção Farmacêutica

0 objetivo em arguir sobre esse ponto derivava do interesse em saber em que proporções havia domínio sobre esse tema e como essa apreensão de conceitos poderia se refletir na construção, na prática diária dos profissionais, de um trabalho com foco no paciente.

$\checkmark$ ia de regra, os entrevistados demonstraram ter pouca compreensão do significado do termo Atenção Farmacêutica, retratando seu pouco contato com essa terminologia. A expressão Atenção Farmacêutica foi confundida com a Assistência Farmacêutica, ou era interpretada como mera aten ção, na acepção de ser agradável e dar ouvidos ao que o paciente fala e não ao propósito de fornecer informações que minimizem o risco de problemas relacionados com os medicamentos.

Atenção Farmacêutica é o farmacêutico estar na drogaria dando atenção ao cliente (farmacêutico de farmácia de rede local).

Entretanto, mesmo sem domínio sobre o termo, mesmo sem estabelecer com precisão as relações das atividades de Atenção com o trabalho clínico, observou-se que certa transição já se processa na prática profissional relatada pelos entrevistados, na medida em que se referem ao paciente como eixo principal do seu trabalho, quando defendem um envolvimento mais específico do profissional com a farmacoterapia e quando reclamam e reiteram a importância da existência de condições concretas paraa realização de atividades técnicas nas farmácias deslocadas para o benefício dos pacientes no uso de seus medicamentos.

Para mim, Atenção Farmacêutica é como eu ajo. É transformar todo 0 aprendizado que eu tive na faculdade em relação à farmacologia em algo que possa favorecer a população em geral, quepossa transformá-la com o meu conhecimento, que possa trazer conhecimento para as pessoas. É agir em prol da qualidade de vida das pessoas (farmacêutico de farmácia de rede estadual).

Significa estar interagindo com o paciente, ouvindo, entendendo o que el equer dizer. $\mathrm{E}$ eu, da forma mais didática, vou orientá-lo para que ele possa realmente aderir ao tratamento e, assim, o medicamento possa realmentefazer efeito. Porque, às vezes, o paciente não sabe ler, e o médico nem sabe que ele é analfabeto. Então, chega no balcão da farmácia ea gente vê que o paciente é humilde e até pergunta de uma forma ou de outra. A gente desenha, faz o desenho de como ele tem quetomar, explica os efeitos. I sso sim, para mim, traduz Atenção Farmacêutica (farmacêutico de farmácia de rede estadual).

0 trabalho de campo permitiu verificar ainda que já são realizadas, pelos farmacêuticos, várias atividades com pontos de convergência com a prática da Atenção Farmacêutica, tais como a orientação farmacêutica e um esboço da dispensação. Elas, entretanto, ainda parecem ser secundárias, executadas muito mais por disponibilidade e interesse intrínsecos de al guns profissionais do que resultando de um processo interiorizado e ampliado de compreensão e val orização por parte da categoria profissional como um todo, de seus órgãos formadores e fiscalizadores e dos estabelecimentos comerciais.

\section{Consideraçõesfinais}

Captar as percepções e os relatos dos farmacêuticos sobre a dinâmica da sua prática profissional mostrou-seum caminho adequado para identificar al guns dos fatores que podem estar impedindo o exercício pleno do farmacêutico como legítimo profissional de saúde nas farmácias comunitárias.

Uma possível limitação do estudo pode ser em razão do perfil da região alvo da pesquisa. Contudo, os achados se alinham com a realidadeobservada pela pesquisadora no cotidiano das fiscalizações nas farmácias comunitárias do estado do Rio de Janeiro, indicando queas diversidades entre as regiões desse estado, no que tange aos aspectos abordados, podem ser pequenas.

N este trabalho, a partir das fal as sobre as trajetórias profissionais e os processos de trabal ho dos farmacêuticos atuantes em três tipos de farmácias comunitárias - familiares, de rede local e de rede estadual -, foi possível identificar pontos considerados críticos no seu cotidiano, bem como a presença de elementos relacionados com o estímulo ou, contrariamente, à obstaculização dos processos relacionados à implantação de práticas deAtenção Farmacêutica nas farmácias edrogarias. Nota-se, ainda, que o itinerário trilhado na prática profissional fica a cargo de cada um, solitariamente, sendo o esforço para prover mudanças no presente paradigma da prática farmacêutica e os méritos desse empenho considerados iso- 
lados, com os caminhos para se chegar ao objetivo desejado se mostrando sinuosos e acidentados.

Os encontros com os entrevistados e a oportunidade de fazê-los refletir ao responder sobre questões vivenciadas da prática profissional indicou, muitas vezes, situações de desânimo presentes nos grupos de farmacêuticos jovens e de redelocal eestadual, quese sentem inibidos profissionalmente pela pressão exercida pela organização das farmácias comunitárias, quanto à realização de ações de orientação e apoio quanto ao uso de medicamentos à população. Muitos desses farmacêuticos, aos poucos, tendem a assumir as posições desejadas pelos seus empregadores de somente se ater ao controle e dispensação demedicamentos da Portaria n $344 / 98$ SVS/ MS, reduzindo o espectro das atividades com foco no paciente e seu processo de cuidado.

Já alguns dos farmacêuticos mais experientes transmitem uma mensagem e uma visão mais otimistas, de que a superação do modelo da atual prática profissional nas farmácias comunitárias é possível e se realiza na medida em que a população os procura e os reconhece como os profissionais do medicamento. Nesses encontros, independentemente da tipologia da farmácia, eles disseram se sentir realizados profissionalmente, quando podiam oferecer aos seus pacientes um cuidado que se expressava em uma efetiva contribuição para a compreensão de seu adoecimento, do processo de cuidado e da meIhor forma de utilização dos medicamentos.

Quando a prática farmacêutica estava associada com o estabelecimento de vínculos, fornecimento de orientações sobre o uso de medicamentos e atitudes de corresponsabilidades no cuidado com o paciente, uma carga maior de satisfação era sentida pelos profissionais na realização de suas atividades nas farmácias.

Temos então a implantação de práticas focadas no paciente, tais como a Atenção Farmacêutica como um dínamo para a mudança do padrão de atitudes e comportamentos encontrados no cotidiano dos farmacêuticos. Apesar de não serem conhecedores do conceito teórico da Atenção Farmacêutica, eles expressam conhecer o valor dessa prática e a concepção de que é necessário haver uma atitude pró-ativa, compromisso com o paciente e uma mudança de comportamento, itens embutidos no conceito brasileiro de Atenção Farmacêutica.

A Atenção Farmacêutica não éuma realidade nas farmácias comunitárias estudadas, e existe um caminho se percorrer até que possa ser. Ter 0 farmacêutico presente nas farmácias, com certeza, éuma grande conquista, mas ter a clareza dos seus limites e das dificuldades que são enfrentadas no exercício da sua prática éum dos imperativos desse momento de revitalização da profissão farmacêutica.

Schostack ${ }^{24}$ ressalta que 0 ato profissional farmacêutico está fundamentado em três princípios: o conhecimento efetivo do medicamento, 0 relacionamento com o usuário de medicamento e com o prescritor do medicamento. 0 que seria esperado da prática farmacêutica ou atenção à saúde nas farmácias seria a integração dessas três matrizes proporcionando novas possibilidades para a profissão, resultando em ações que garantissem que o uso do medicamento viesse a ocorrer com eficácia esegurança, visando atingir resultados terapêuticos definidos na saúde e na qualidade de vida do paciente, atendendo assim a proposta inicial de Atenção Farmacêutica de H epler e Strand ${ }^{25}$.

As questões apontadas neste artigo suscitam a recondução do debate acerca dos el ementos necessários para o melhor desempenho da prática farmacêutica nas farmácias comunitárias, direcionada a maximizar a contribuição de sua atuação profissional para as necessidades relacionadas ao uso demedicamentos pela sociedade. Nessa perspectiva, é preciso salientar que a mudança do paradigma ainda é um projeto, um percurso. É uma trajetória a ser buscada. Podemos sugerir um caminho: onde 0 interesse maior para esse projeto profissional esteja voltado para o seu trajeto, isto é, para o processo de implementação dessa prática.

\section{Colaboradores}

CRG Bastos trabalhou na organização e execução da pesquisa e na concepção teórica, elaboração e redação do texto; R Caetano participou como orientadora durante todas as etapas da elaboração do artigo, colaborando na análise crítica do texto, redação e revisão final. 


\section{Agradecimentos}

Ao Instituto de M edicina Social da Universidade do Estado do Rio de Janeiro pela iniciativa em oferecer aos alunos dos cursos de mestrado e doutorado do Departamento de Planejamento e

Referências

1. Brasil. Secretaria de Acompanhamento Econômico do M inistério da Fazenda. Preços de medicamentos no Brasil e a atuação da SEAE em 1999. [acessado 2007 nov 11]. Disponível em http://www.fazenda.gov. $\mathrm{br} /$ seae/documentos/Precomedi.html

2. Brasil. Lei n 5.991, de 17 de dezembro de 1973. Dispõe sobre o controle sanitário do comércio de drogas, medicamentos, insumos farmacêuticos e correlatos, e dá outras providências. Diário Oficial da União 1973; 19 dez.

3. Cipolle R, Strand L, M orley C. 0 exercício do cuidado farmacêutico. Brasília: Conselho Federal de Farmácia; 2006.

4. Martin-Calero MJ, Machuca M, Murillo MD, Cansino J, Gastelurrutia MA, Faus MJ. Structural process and implementation programs of pharmaceutical care in different countries. Current Pharmaceutical Design 2004; 10(31): 3969-3985.

5. Cipolle RJ, Strand L, M orley PC. Pharmaceutical care practice: the clinican's guide. $2^{\text {nd }} \mathrm{ed}$. New York: McGraw Hill; 2004.

6. Cipolle RJ. Drug's don't have doses: people have doses. Drug Intell Clin Pharm 1986; 20:881-882.

7. Ivama AM, Noblat L, Castro MS, Oliveira NVBV, Jaramillo N M, Rech N. Consenso Brasileiro de Atenção Farmacêutica: proposta. Brasília: Organização Pan-Americana da Saúde; 2002.

8. Brasil. Portaria n 3.916, de 30 de outubro de 1998. Aprova a Política Nacional de M edicamentos. Diário Oficial da União 1998; 10 nov.

9. Araújo ALA, Freitas O. Concepções do profissional farmacêutico sobre a assistência farmacêutica na Unidade Básica de Saúde: dificuldades e elementos para a mudança. Rev Bras Ciênc Farm 2006; 42(1):137-146.

10. Estefan IJS. 0 ensino de farmácia. Cad Saude Publica 1986; 2(4):511-532.

11. Bastos CRG. Tem farmacêutico na farmácia: as percepções dos farmacêuticos sobre seu trabalho nas farmácias comunitárias do estado do Rio de Janeiro [dissertação]. Rio de Janeiro: Instituto de M edicina Social, Universidade do Estado do Rio de Janeiro; 2007.

12. Brasil. Conselho Nacional de Saúde. Comissão Nacional de Ética em Pesquisa. N ormas para pesquisa envolvendo seres humanos: Resolução CN S $n^{\circ}$ 196/96 e outras. Brasília: M inistério da Saúde; 2000. (Série Cadernos Técnicos).

13. Fontanella BJB, Ricas J, Turato ER. Amostragem por saturação em pesquisas qualitativas em saúde: contribuições teóricas. Cad Saude Publica 2008; 24(1):17-27.
Administração em Saúde a Oficina de Artigos Científicos, desejando que essa iniciativa setorne uma constante na instituição. Em especial, aos professores Kenneth Rochel de Camargo J r., Roseni Pinheiro e Ruben Araujo de Mattos, pelas discussões e contribuiç̧ões ao longo do processo de elaboração do artigo.

14. Bardin L. Análise de conteúdo. Lisboa: Edições 70; 1977.

15. Naves JOS, M erchan-Hamann E, Silver LD. Orientação farmacêutica para DST: uma proposta de sistematização. Cien Saude Colet 2005; 10(4):1005-1015.

16. Ávila ARF, Bastos CRG. Aspectos do comércio farmacêutico privado em regiões do município do Rio de Janeiro. In: I Congresso de Ciências Farmacêuticas do Rio de Janeiro, 1999. Resumo dos trabaIhos. Rio de Janeiro: CRF-RJ; 1999.

17. Brasil. Lei no 9.787, de 10 de fevereiro de 1999. Altera a Lei $n^{\circ} 6.360$, de 23 de setembro de 1976, que dispõe sobre a vigilância sanitária, estabelece o medicamentos genérico, dispõe sobre a utilização de nomes genéricos em produtos farmacêuticos e dá outras providências. Diário O ficial da U nião 1999; 11 fev.

18. Brasil. Portaria no 344, de 12 de maio de 1998. Regulamento Técnico sobre Substâncias e M edicamentos sujeitos a Controle Especial. Diário Oficial da União 1998; 15 maio.

19. Zubioli A. Ética farmacêutica. São Paulo: Sobravime; 2004.

20. Canesqui AM. Estudos socioantropológicos sobre os adoecidos crônicos. In: Canesqui AM, organizadora. Olhares socioantropológicos sobre os adoecidos crônicos. São Paulo: Hucitec; 2007. p.19-52.

21. Loyola M A. M édicos e curandeiros. São Paulo: Difel; 1984.

22. Luiza VL, Bermudez JAZ. Acesso a medicamentos: conceitos e polêmicas. In: Bermudez JAZ, organizador. Acesso a medicamentos: derecho fundamental, papel del Estado. Rio de Janeiro: Escola Nacional de Saúde Pública Sergio Arouca; 2004. p. 45-67.

23. Éboli GB. A função social do farmacêutico. Pharm Bras Brasília 2002; 3(32):35.

24. Schostack J. Atenção Farmacêutica. Porto Alegre: Publicações Biomédicas; 2004.

25. Hepler CD, Strand LM. Opportunities and responsabilities in pharmaceutical care. Am J Hosp Pharm 1990; 47:533-543.

Artigo apresentado em 30/11/2007

Aprovado em 25/03/2008

Versão final apresentada em 25/04/2008 